\title{
Cambios en las prescripciones y el consumo de antimicrobianos, luego de la implementación de recomendaciones de uso: experiencia en un hospital universitario
}

\author{
Fernanda Ávila', Mario Luppi', Pablo Gaete', Alejandra Rivas², Francisco Silva' y Roberto Olivares ${ }^{1}$
}

\section{Changes in prescriptions and antibiotic consumption after the implementation of recommendations for use: experience in a university hospital}

Background: Nowadays about half of antibiotic prescriptions are inadequate, increasing bacterial resistance. Both cephalosporins and fluoroquinolones are associated with this phenomenon: increase of $\beta$-lactamase producing bacteria and Clostridioides difficile infections, which is why regulatory agencies seek to rationalize their use. Aim: To evaluate the effect of use recommendations on the proportion of inadequate prescriptions of ceftriaxone and fluoroquinolones. Methods: A prospective and interventional study was developed, comparing the quality and quantity of use of ceftriaxone and fluoroquinolones before and after the implementation of use recommendations for treatments of infectious diseases acquired at the community. The outcomes were: proportion of inadequate prescriptions and defined daily dose (DDD). Data were analyzed using the Chi-square test, Fisher's correction and Student's test. Results: A total of 206 patients were evaluated, a 35\% decrease in inadequate prescriptions, a decline in the consumption of ceftriaxone and levofloxacin, and a significant increase in the use of ampicillin/ sulbactam was observed. Conclusions: The implementation of use recommendations based on scientific evidence and local susceptibility allowed to reduce the proportion of inadequate prescriptions and to reduce de consumption of ceftriaxone and fluoroquinolones.

Keywords: Antibiotics, ceftriaxone, quinolones, antimicrobial stewardship.

Palabras clave: Antimicrobianos, ceftriaxona, quinolonas, uso racional de antimicrobianos.

\section{Introducción}

$\mathrm{C}$ on la aparición de los antimicrobianos (AMs) se ha logrado controlar un gran número de enfermedades infecciosas y disminuir su mortalidad ${ }^{1,2}$; sin embargo, con el paso de los años su utilización se ha convertido en un problema global; en estudios observacionales, tanto de centros ambulatorios como hospitalarios, cerca de $50 \%$ de las prescripciones de AMs son inadecuadas ${ }^{3-5}$, ya sea por su uso injustificado, por una elección incorrecta dada la patología o el agente bacteriano o, en algunos casos, una correcta indicación pero inapropiado uso (dosis) ${ }^{4}$. El uso inadecuado de AMs, genera selección de cepas bacterianas resistentes y disminución de alternativas terapéuticas ${ }^{6}$, lo que se asocia a fracasos de tratamientos, extensión de estadías hospitalarias, aumento de morbilidad, mortalidad y $\operatorname{costos}^{7,8}$.

Por esto, las agencias reguladoras respaldan iniciativas que tiendan a disminuir y mejorar el uso de $\operatorname{los} \mathrm{AMs}^{1,8}$. Todas las clases de AMs se relacionan con la resistencia bacteriana; sin embargo, cefalosporinas y fluoroquino- lonas (FQ) se han asociado en mayor medida con este fenómeno, ${ }^{9,10}$.

El uso desmedido de FQ se relaciona principalmente con la expresión de mecanismos de resistencia en bacterias gramnegativas ${ }^{11}$ y mayor riesgo de aislamiento e infección clínica por Staphylococcus aureus resistente a meticilina (SARM), Enterococcus resistente a vancomicina (ERV) y Clostridioides difficile ${ }^{12}$. El uso excesivo de FQ también se asocia con un aumento de la resistencia de Pseudomonas aeruginosa, la que a su vez se relaciona con menor susceptibilidad a otra clase de $\mathrm{AMs}^{13}$.

Por otro lado, el uso prolongado de cefalosporinas de tercera generación se relaciona con un aumento de bacterias productoras de $\beta$-lactamasas de espectro extendido (BLEE) y representa un factor de riesgo para infecciones por $C$. difficile ${ }^{9,14}$, agente considerado en E.U.A. como el principal causante de infecciones asociadas a la atención de salud ${ }^{15}$. En nuestro centro, según datos del año 2015, Escherichia coli posee cerca de $20 \%$ de resistencia a cefalosporinas de tercera generación, mientras que Klebsiella pneumoniae alcanza a 50\%.

En estudios chilenos se observó que el principal factor

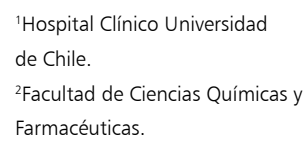

Recibido: 31 de marzo de 2017

( $1^{\circ}$ versión), 29 de enero de 2019 (versión definitiva). Aceptado: 5 de febrero de 2019

Correspondencia a:

Fernanda Ávila Oesterle fdaavilao@gmail.com 
presente en los pacientes que desarrollaron infecciones por $C$. difficile, fue haber estado expuestos previamente a antibioterapias con FQ o cefalosporinas de tercera generación ${ }^{16,17}$.

Tanto las infecciones por bacterias productoras de BLEE como por $C$. difficile tienen un profundo impacto económico en los sistemas de salud. En E.U.A., el costo promedio y la estadía hospitalaria para los casos de $C$. difficile fue significativamente mayor al compararlos con pacientes $\sin C$. difficile ${ }^{18}$, mientras que las infecciones por microogranismos resistentes fue un predictor significativo de mortalidad y aumento de estadía hospitalaria ${ }^{19}$.

Debido al dramático aumento de la resistencia bacteriana, las agencias reguladoras proponen ciertas intervenciones: restringir el uso de FQ y cefalosporinas ${ }^{9,20}$ reducir los días de tratamiento AMs, reducir los días de tratamiento $\mathrm{AMs}^{21}$, cambio a terapia oral precozmente ${ }^{21}$, ajuste de tratamientos según la microbiología en cada institución de salud, uso de otra clases de AMs, como penicilinas y tetraciclinas, entre otros ${ }^{4,22}$.

En nuestro país, para el año 2008 ceftriaxona fue el AM más consumido en el medio hospitalario, representando diariamente cerca de 18 tratamientos por cada 100 camas ocupadas. Ciprofloxacina registró valores promedio de 0,68 DDD/100 día/cama ${ }^{23}$. En nuestro centro, el año 2013 el consumo de ceftriaxona fue de $8,4 \mathrm{DDD} / 100$ días cama, mientras que ciprofloxacina y levofloxacina fueron de 2,54 y 1,86 DDD/100 camas día respectivamente. Dichos valores se asemejan a las tendencias internacionales, donde las cefalosporinas de tercera generación habitualmente aparecen como los AM de elección ${ }^{24-26}$.

La implementación de recomendaciones de uso (RU) basadas en la evidencia científica y en la microbiología propia de cada instutución parece ser una estrategia fundamental para controlar la resistencia bacteriana. Si bien los tratamientos deben ser individualizados, paciente a paciente, estas recomendaciones buscan entregar el marco científico para una elección racional del agente $\mathrm{AM}^{27}$.

El cumplimiento de RU ha demostrado tener un efecto beneficioso en los resultados clínicos, estadía hospitalaria y $\operatorname{costos}^{27}$, disminuyendo de 40 a $20 \%$ las prescripciones inadecuadas de $\mathrm{AM}^{1} \mathrm{y}$ reduciendo las tasas de infecciones nosocomiales ${ }^{28-30}$.

Sin embargo, en Chile no se han publicado estudios que muestren el efecto de intervenciones dirigidas a controlar los tratamientos empíricos para infecciones de la comunidad, donde existe alta prescripción de cefalosporinas y FQ.

El objetivo principal de nuestro estudio fue determinar, el efecto de la implementación de RU, en la proporción de prescripciones inadecuadas de AMs en pacientes hospitalizados, buscando disminuir la utilización esencialmente de ceftriaxona y FQ. Los objetivos específicos fueron evaluar el efecto en la calidad y el consumo de
AM, además del impacto en los días de hospitalización, de tratamiento AM y la cura clínica de pacientes.

\section{Pacientes y Método}

Diseño del estudio: Durante el período comprendido entre abril del año 2014 y mayo de 2015 , se realizó un estudio de antes y después, prospectivo, intervencional, en el Hospital Clínico de la Universidad de Chile (HCUCH).

Esta investigación fue aprobada por el Comité de Ética Científico del establecimiento y tuvo la colaboración de la Facultad de Ciencias Químicas y Farmacéuticas de la Universidad de Chile, para el análisis e interpretación de datos.

El tamaño muestral se determinó por medio del programa estadístico STATA $^{\circledR}$, considerando $50 \%$ de prescripciones inadecuadas de AM pre intervención y buscando lograr una disminución de $30 \% 0^{3,4}$, con $95 \%$ de confianza y $80 \%$ de potencia; se obtuvo así una muestra de 103 pacientes en cada etapa.

\section{Criterios de inclusión}

Pacientes mayores de 18 años, internados en todo servicio clínico del HCUCH, exceptuando Psiquiatría, con diagnóstico o sospecha diagnóstica por su médico tratantes de: neumonía adquirida en la comunidad (NAC), infección del tracto urinario (ITU), infección intraabdominal (IIA) o meningitis bacteriana aguda (MBA).

Cada diagnóstico fue extraído de la ficha clínica electrónica de los pacientes, sin tener injerencia en el método diagnóstico o en los criterios utilizados para ello. Se excluyeron aquellos pacientes que su hospitalización comprendió solamente los días donde no se realizó vigilancia (fines de semana o feriados), dado que no fueron captados para ingresarlos al estudio.

\section{Descripción del estudio (Figura 1)}

En la Fase I del estudio, comprendida entre abril y septiembre de 2014, se revisó diariamente el diagnóstico de ingreso de todos los pacientes internados en el HCUCH y se registraron aquellos pacientes que tuvieran algunos de los diagnósticos incluidos en el estudio (NAC, ITU, IAA, MBA) que están codificados en la ficha clínica electrónica. Esta revisión fue realizada por el Químico Farmacéutico miembro del equipo.

Posteriormente, se revisaron sus antecedentes y se recolectó la información de los primeros 103 pacientes que cumplieran con los criterios de inclusión. Se incluyeron datos de antecedentes personales, esquema AM prescrito, evolución de enfermedad infecciosa y exámenes de laboratorio. Aquellos pacientes que ingresaron con determinado diagnóstico y que posteriormente se desestimó, no fueron excluidos. 


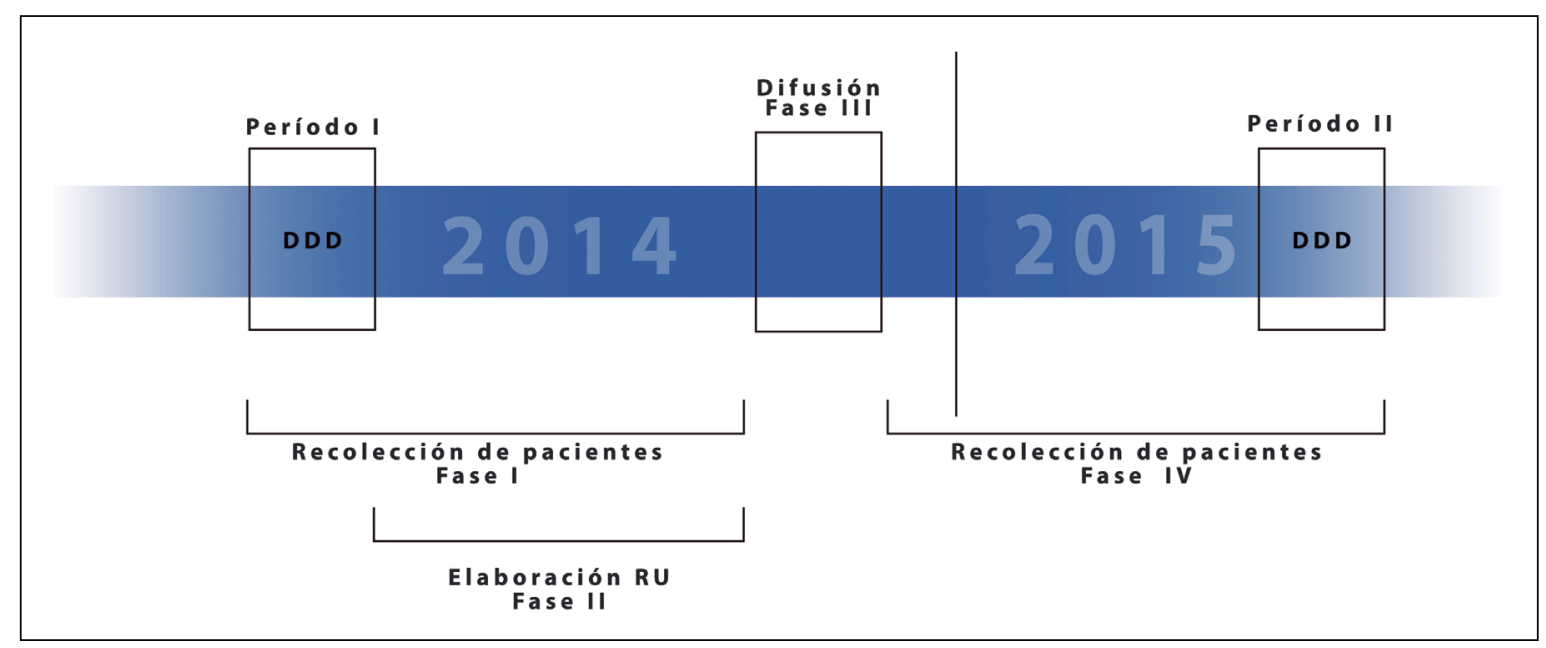

Figura 1. Esquema de trabajo. ${ }^{*} \mathrm{DDD}$ : Dosis Diarias Definidas. Fase I: Recolección información de pacientes pre intervención. Fase II: Elaboración de las recomendaciones de uso para los tratamientos empíricos de enfermedades adquiridas en la comunidad. Fase III: Difusión de las recomendaciones de uso. Fase IV: Recolección de información de pacientes post-intervención.
Paralelamente a la Fase I, se elaboraron las RU propuestas para los tratamientos empíricos de NAC, ITU, IIA y MBA (Fase II). Para el diseño de las RU se realizaron revisiones de las principales guías clínicas disponibles para el tratamiento de estas patologías ${ }^{31-32,41-45,33-40}$.

Además, se analizaron y ajustaron las propuestas de tratamientos según la microbiología nacional y la del propio hospital. Finalmente se apoyaron las recomendaciones con evidencia actualizada encontrada, tanto de buscadores como MEDLINE, OVID y LILAC. Dentro de los parámetros de búsqueda estuvo el idioma inglés y español, además de publicaciones entre los años 2000 y 2014. Los trabajos seleccionados fueron principalmente revisiones, revisiones sistemáticas, guías clínicas, metaanálisis y estudios clínicos controlados. Todas las RU fueron elaboradas por un grupo formado por: Médicos Infectólogos, Químicos Farmacéutico y Médico Microbiólogo del establecimiento.

Para la generación de las RU se consideró la realidad del establecimiento, las prácticas clínicas habituales, el arsenal terapéutico disponible y la población atendida, ajustando las intervenciones a dichos criterios. El principal objetivo fue la facilidad de su comprensión y aplicación por parte del cuerpo médico.

Previa a la difusión de las RU, éstas fueron entregadas a los distintos servicios clínicos para su revisión, en búsqueda de sugerencias y comentarios, recibiendo respuesta en $25 \%$ de los servicios. Posteriormente, y durante dos meses (octubre y noviembre de 2014), se difundieron por medio de capacitaciones al cuerpo médico y entrega de trípticos impresos y en formato digital. Además, se facilitaron afiches para ser exhibidos (Fase III). Durante este período no hubo enrolamiento de pacientes.

Posteriormente a la difusión de las RU, se recolectó la información de los primeros 103 nuevos pacientes que cumplieran los criterios de inclusión (Fase IV, desde diciembre de 2014 a mayo de 2015), de igual forma que previo a la intervención.

Para medir el efecto en la calidad de la utilización de $A M s$, se compararon los datos recolectados pre y post intervención, con respecto a las RU elaboradas, como se muestra en la Figura 2. Desde el punto de vista operacional, se definió como "prescripción inadecuada" aquella que no se ajustaba a las RU. La evaluación de cada una de

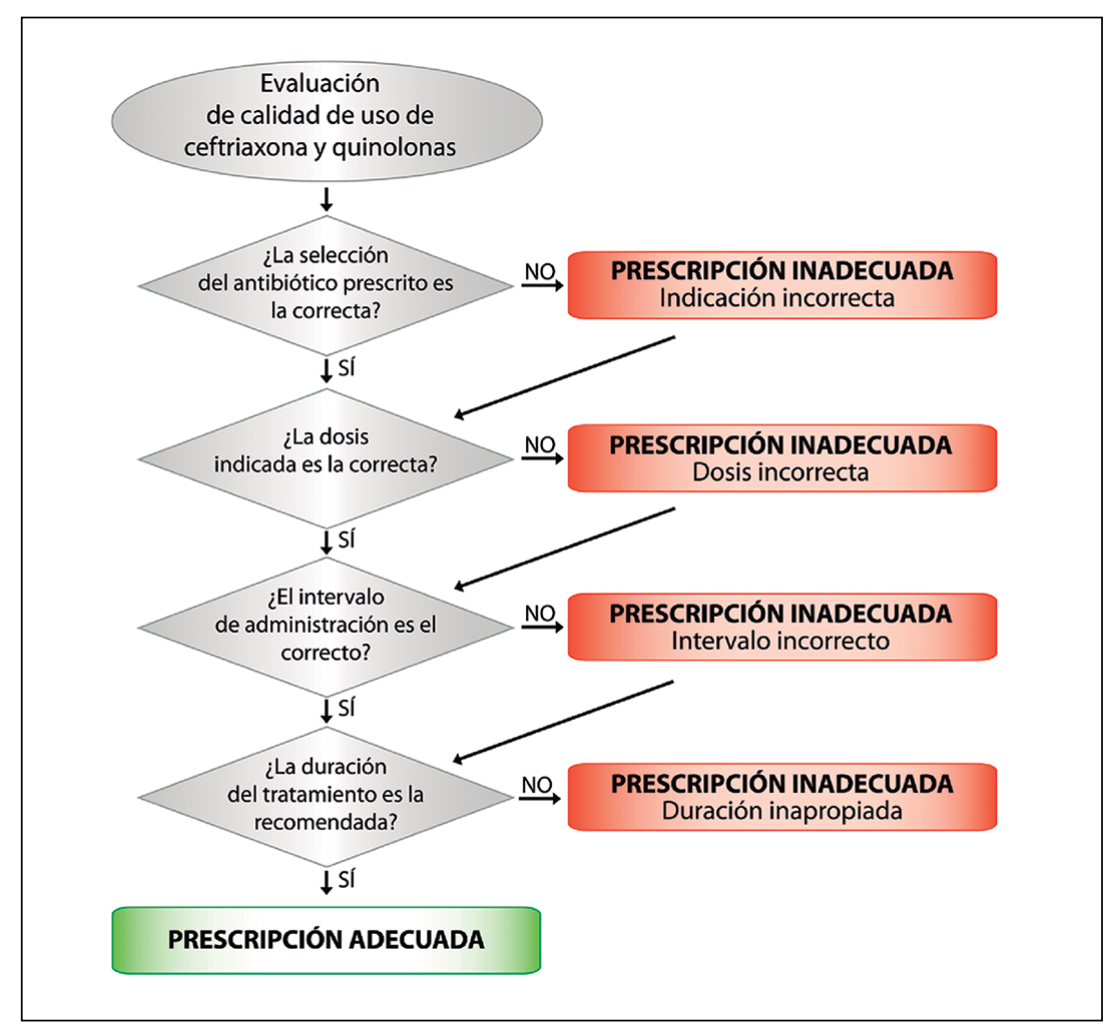

Figura 2. Flujograma para evaluación de la calidad de utilización de antimicrobianos. 
las prescripciones fue realizada por el Químico Farmacéutico y los Infectólogos, quienes no tuvieron injerencia en la decisión del tratamiento AM indicado a los pacientes, ni antes ni después de la intervención.

Para establecer el éxito de la intervención se usó como indicador de calidad la proporción de prescripciones inadecuadas de AM, calculada como la razón entre el número de prescripciones inadecuadas con respecto al número de prescripciones totales.

Para medir el efecto de las RU en la cantidad de utilización de AMs se utilizó la metodología de las DDD/100 días/camas ocupadas, que fue calculada por medio de los datos aportados por el Servicio se Farmacia y la Unidad de Estadística del HCUCH.

Para medir el impacto de las RU en el consumo de AMs, se calcularon las DDD/100 camas/días del período post intervención, comparándolo con el mismo período del año anterior (previa difusión), con el fin de anular el efecto de la estacionalidad en el consumo de AMs. Se estableció arbitrariamente, como período I desde el 20 de abril al 15 de mayo de 2014 y como período II, desde

Tabla 1. Esquemas de tratamiento utilizados pre intervención y post intervención

Esquemas de tratamientos
$\begin{gathered}\text { Pre intervención } \\ \begin{array}{c}\text { Usados espontáneamente por el equipo } \\ \text { médico }\end{array}\end{gathered}$
Necomentados por el equipo
de Infectología
Tratamiento hospitalizados en sala CURB 65: 2-3

Ceftriaxona $1 \mathrm{~g}$ cada $12 \mathrm{~h}$ ev + levofloxacina 500-750 mg cada $24 \mathrm{~h}$ vo/ev

Ceftriaxona $1 \mathrm{~g}$ cada $12 \mathrm{~h} \mathrm{ev}+$ levofloxacina 500-750 mg cada $24 \mathrm{~h}$ ev
Amoxicilina/ácido clavulánico 875/125 mg cada 12 h vo + claritromicina 500 mg cada $12 \mathrm{~h}$ vo por 5-7 días

Ampicilina/sulbactam $3 \mathrm{~g}$ cada $8 \mathrm{~h}$ ev + claritromicina $500 \mathrm{mg}$ cada $12 \mathrm{~h}$ ev por 5-7 días

Tratamiento hospitalizado en Unidad de Paciente Crítico CURB 65: $\geq 4$

Ceftriaxona $1 \mathrm{~g}$ cada $12 \mathrm{~h} \mathrm{ev}+$ levofloxacina 500-750 mg cada $24 \mathrm{~h}$ ev

Ampicilina/sulbactam $3 \mathrm{~g}$ cada $8 \mathrm{~h}$ ev + claritromicina $500 \mathrm{mg}$ cada $12 \mathrm{~h}$ ev por 7-10 días

\section{Infecciones del tracto urinario}

Alta

Ceftriaxona $1 \mathrm{~g}$ cada $12 \mathrm{~h} \mathrm{ev}$

Amikacina $15 \mathrm{mg} / \mathrm{kg}$ cada $24 \mathrm{~h} \mathrm{ev}$ Ajustar con resultado de urocutivo' En caso de falla renal: Ceftriaxona $1 \mathrm{~g}$ cada $12 \mathrm{~h}$

\section{Infecciones intra-abdominales}

Ceftriaxona $1 \mathrm{~g}$ cada $12 \mathrm{~h}$ ev + metronidazol Ampicilina/sulbactam $1,5 \mathrm{~g}$ cada $8 \mathrm{~h}$ ev $500 \mathrm{mg}$ cada $8 \mathrm{~h}$ ev

\section{Menigitis bacteriana aguda}

Ceftriaxona $2 \mathrm{~g}$ cada $12 \mathrm{~h}$ ev Ceftriaxona 2 g cada 12 h ev por 10-14 días

'En pacientes sin factores de riesgo para toxicidad. ${ }^{2} E n$ casos de mayor gravedad se recomendó dosis de $3 \mathrm{~g}$ cada 6 h. La duración del tratamiento se evaluó caso a caso. el 20 de abril al 15 de mayo del año 2015, pre y postintervención, respectivamente.

Para el cálculo de las DDD/100 camas /día, se incluyeron los AMs considerados dentro de las RU: ceftriaxona, ciprofloxacina, levofloxacina, amikacina, ampicilina/ sulbactam y claritromicina. Se incluyeron todos los servicios clínicos del establecimiento, excluyendo Pediatría, debido a que las recomendaciones estaban enfocadas en pacientes adultos.

Los outcomes primarios del estudio fueron: prescripciones inadecuadas de AMs y DDD/100 camas/día de AMs.

Los outcomes secundarios fueron: días de hospitalización, días de tratamiento AM y cura clínica (considerada como aquella establecida por el médico tratante; no obstante, en general fue disminución de parámetros inflamatorios, ausencia de fiebre y mejoría de síntomas).

\section{Análisis estadístico}

Para el análisis de los datos se utilizó Microsoft Excel, mientras que para los outcomes primarios: proporción de prescripciones inadecuadas de AMs y el consumo de AMs por medio de las DDD/100 camas /días, se utilizó el test de $\chi^{2}$, corrección de Fisher y test de Student, con $5 \%$ de significancia y un análisis de dos colas por medio de Microsoft Excel, Epi Info y STATA.

\section{Resultados}

\section{Elaboración de las recomendaciones de uso}

Antes de la intervención, cada médico prescribía esquemas de tratamientos para las distintas patologías, que no formaban parte de recomendaciones oficiales del establecimiento. Posteriormente, las RU implementadas sugirieron esquemas de tratamientos basados en familias de AMs que se asocian en menor medida con la resistencia bacteriana, como son aminoglucósidos, macrólidos y penicilinas en asociación con inhibidores de $\beta$-lactamasas, entre otros ${ }^{9,20}$. Los esquemas utilizados previamente y cambios propuestos en cada una de las patologías se muestran en la Tabla 1.

\section{Características basales de la muestra}

De un total de 206 pacientes estudiados, 53,9\% fueron mujeres, con un promedio de edad de 59,5 \pm 20 años. Hipertensión arterial $(46,1 \%)$ y diabetes mellitus (20,9\%) fueron las dos co-morbilidades más frecuentes. Los pacientes del estudio presentaban como principal factor de riesgo de resistencia bacteriana el uso de AM en los tres meses previos. No se observaron diferencias estadísticamente significativas entre los grupos pre y post-intervención, excepto en el porcentaje de pacientes obesos y el foco de infección. Los pacientes obesos fueron 
mayoritarios en el grupo pre-intervención al igual que la existencia de un foco respiratorio, mientras que en grupo post intervención el foco abdominal fue el más frecuente (Tabla 2).

Previo a la intervención, de los 32 pacientes incluidos con IIA, 90,6\% recibió tratamiento con ceftriaxona y metronidazol y $9,4 \%$ con ciprofloxacina y metronidazol. Con respecto a los pacientes con NAC $(\mathrm{n}=38), 100 \%$ fue tratado con esquemas basados en ceftriaxona y levofloxacina. Mientras que de los pacientes con ITU $(n=32)$, $59,4 \%$ recibió ciprofloxacina y 40,6\% ceftriaxona.

\section{Evaluación del efecto de $R U$ en la disminución de la proporción de prescripciones inadecuadas de $A M s$}

Luego de la implementación de las RU, la proporción de prescripciones inadecuadas de AMs disminuyó en 35\% con respecto al basal. Previo a la difusión, las prescripciones inadecuadas alcanzaban a $83 \%$, disminuyendo de forma significativa a $53 \%(\mathrm{p}<0,05)$.

Los indicadores que presentaron mayores variaciones fueron las indicaciones y las duraciones inadecuadas. Las indicaciones inadecuadas disminuyeron de 73,5 a 49,5\%

\begin{tabular}{|c|c|c|c|c|}
\hline Variable & $\begin{array}{c}\text { Antes } \\
\text { n (\%) }\end{array}$ & $\begin{array}{c}\text { Después } \\
\text { n (\%) }\end{array}$ & $\begin{array}{l}\text { Total } \\
\text { n (\%) }\end{array}$ & $\mathbf{p}$ \\
\hline \multicolumn{5}{|l|}{ Sexo } \\
\hline Hombres & $48(46,6 \%)$ & $47(45,6 \%)$ & $95(46,1 \%)$ & \multirow[t]{2}{*}{0,89} \\
\hline Mujeres & $55(53,4 \%)$ & $56(54,4 \%)$ & $111(53,9 \%)$ & \\
\hline Edad promedio (años) $\pm \mathrm{DE}$ & $60,3 \pm 19,7$ & $58,6 \pm 20,1$ & $59,5 \pm 19,9$ & 0,54 \\
\hline \multicolumn{5}{|l|}{ Co-morbilidades } \\
\hline Hipertensión arterial & $54(52,4 \%)$ & $41(39,8 \%)$ & $95(46,1 \%)$ & 0,07 \\
\hline Consumo de tabaco & $32(31,1 \%)$ & $24(23,3 \%)$ & $56(27,2 \%)$ & 0,21 \\
\hline Diabetes mellitus & $26(25,2 \%)$ & $17(16,5 \%)$ & $43(20,9 \%)$ & 0,12 \\
\hline Patologías cardiacas & $18(17,5 \%)$ & $13(12,6 \%)$ & $31(15 \%)$ & 0,33 \\
\hline Enfermedad renal & $14(13,6 \%)$ & $10 \quad(9,7 \%)$ & $24(11,7 \%)$ & 0,39 \\
\hline Obesidad & $14(13,6 \%)$ & $4 \quad(3,9 \%)$ & $18 \quad(8,7 \%)$ & 0,02 \\
\hline Patologías respiratorias & $8(7,8 \%)$ & $8 \quad(7,8 \%)$ & $16(7,8 \%)$ & 1,00 \\
\hline Diálisis & $8 \quad(7,8 \%)$ & $5 \quad(4,9 \%)$ & $13(6,3 \%)$ & 0,39 \\
\hline Daño hepático & $2(1,9 \%)$ & $9 \quad(8,7 \%)$ & $11 \quad(5,3 \%)$ & 0,06 \\
\hline Consumo de drogas & $1 \quad(1 \%)$ & $3 \quad(2,9 \%)$ & $4 \quad(1,9 \%)$ & 0,62 \\
\hline Alergia a penicilinas & $1 \quad(1 \%)$ & $3(2,9 \%)$ & $4 \quad(1,9 \%)$ & 0,62 \\
\hline Otras co-morbilidades & $62(60,2 \%)$ & $65(63,1 \%)$ & $127(61,7 \%)$ & 0,67 \\
\hline Antecedentes quirúrgicos & $64(62,1 \%)$ & $64(62,1 \%)$ & $128(62,1 \%)$ & 1,00 \\
\hline \multicolumn{5}{|l|}{ Factores de riesgo para resistencia bacteriana } \\
\hline Uso de AMs en los 3 meses previos & $29(28,2 \%)$ & $27(26,2 \%)$ & $56(27,2 \%)$ & 0,75 \\
\hline Hospitalizaciones en los 3 meses previas & $16(15,5 \%)$ & $18(17,5 \%)$ & $34(16,5 \%)$ & 0,71 \\
\hline Inmunosupresión & $18(17,5 \%)$ & $14(13,6 \%)$ & $32(15,5 \%)$ & 0,44 \\
\hline Otros factores de riesgo & $8(7,8 \%)$ & $8(7,8 \%)$ & $16(7,8 \%)$ & 1,00 \\
\hline \multicolumn{5}{|l|}{ Foco de infección } \\
\hline Abdominal & $32(31,3 \%)$ & $50(48,5 \%)$ & $82(39,8 \%)$ & 0,01 \\
\hline Respiratorio & $38(36,9 \%)$ & $22(21,4 \%)$ & $60(29,1 \%)$ & 0,02 \\
\hline Genitourinario & $32(31,1 \%)$ & $29(28,2 \%)$ & $61(29,6 \%)$ & 0,76 \\
\hline Sistema nervioso central & $1(1 \%)$ & $1(1,9 \%)$ & $3(1,5 \%)$ & 1,00 \\
\hline \multicolumn{5}{|c|}{$\begin{array}{l}\text { *DE: desviación estándar. }{ }^{* *} \text { Otras co-morbilidades: dislipidemia, hipotiroidismo, depresión, cáncer, demencia, Parkinson, entre } \\
\text { otros. }{ }^{* *} \text { Otros factores de riesgo: infecciones de tracto urinario recurrentes, cuadros de Clostridioides difficile tratados, paciente institu- } \\
\text { cionalizado, entre otros. }\end{array}$} \\
\hline
\end{tabular}


(33,3\% de variación). Con respecto a las duraciones inadecuadas la variación registrada fue de $69,7 \%(32,4$ a 9,9\%), siendo ambas estadísticamente significativas (Figura 3).

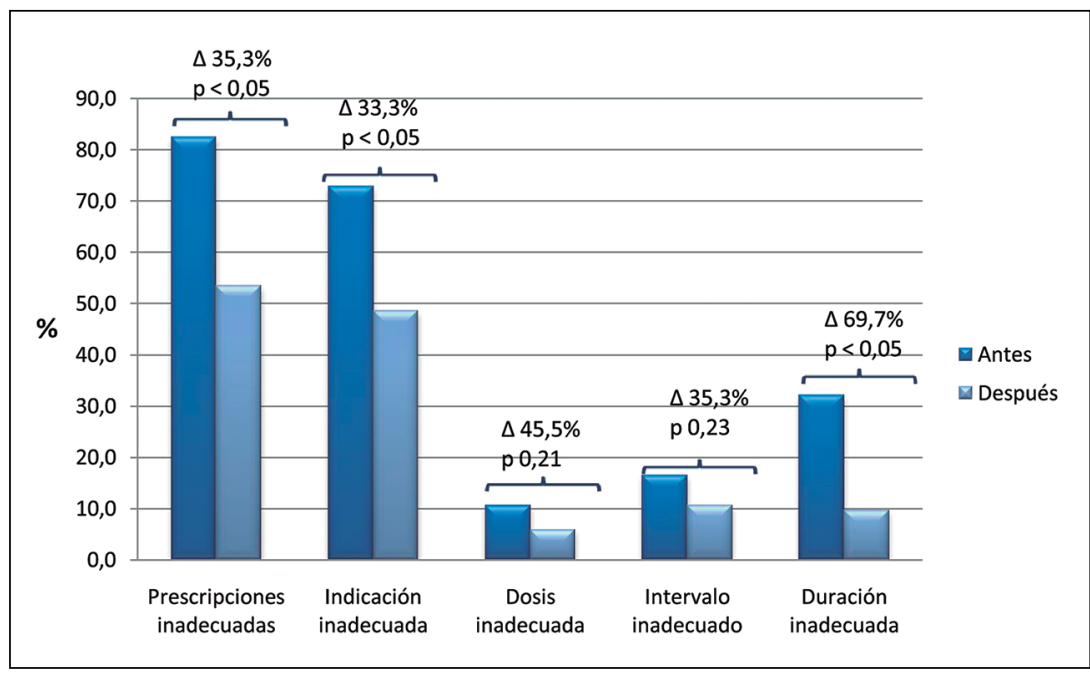

Figura 3. Proporción de prescripciones inadecuadas antes y después de la difusión de las recomendaciones de uso. $\Delta$ : Variación con respecto al porcentaje basal.
Comparación de la calidad de la utilización de AMs antes y después de la implementación de las $R U$

Antes de la difusión de las RU, $100 \%$ de las prescripciones fueron inadecuadas, según las nuevas recomendaciones, tanto para el foco abdominal como respiratorio, siendo la indicación inadecuada el más frecuente (Tabla 3).

Al realizar el análisis por indicadores de calidad de uso de AM, se observó que luego de implementación de las RU, disminuyeron las indicaciones inapropiadas en todos los focos, excepto en el foco genito-urinario que presentó un aumento de 15,6 a 31\%.

Con respecto a los outcomes secundarios, se observó una disminución significativa en el promedio de días de hospitalización luego de la implementación de las RU $(19,8 \pm 38,5$ antes de la implementación vs $8,9 \pm 7,2$ días post-intervención), siendo en el foco abdominal donde se observó la diferencia más significativa (Tabla 3 ).

La cura clínica de los pacientes ( 76,5 vs $80,2 \%$ p: 0,52) y los días de antibioterapia $(10,41 \pm 5,4$ vs $9,5 \pm 6$ p: 0,27$)$ no cambiaron significativamente pre y post-intervención.

Antes de la implementación de las RU, 97\% de los pacientes con diagnóstico o sospecha de IIA recibió terapia combinada, disminuyendo a 78\% luego de la intervención. En el caso de las infecciones respiratorias,

\begin{tabular}{|c|c|c|c|c|c|c|c|c|c|c|c|c|}
\hline \multirow[t]{2}{*}{ Variable } & \multicolumn{3}{|c|}{$\begin{array}{l}\text { Foco abdominal } \\
n=82\end{array}$} & \multicolumn{3}{|c|}{$\begin{array}{c}\text { Foco respiratorio } \\
n=60\end{array}$} & \multicolumn{3}{|c|}{$\begin{array}{l}\text { Foco genitourinario } \\
\qquad n=61\end{array}$} & \multicolumn{3}{|c|}{$\begin{array}{l}\text { Total } \\
n=206\end{array}$} \\
\hline & $\begin{array}{c}\text { Antes } \\
n=32 \\
n(\%)\end{array}$ & $\begin{array}{c}\text { Después } \\
n=50 \\
n(\%)\end{array}$ & p & $\begin{array}{c}\text { Antes } \\
n=38 \\
n(\%)\end{array}$ & $\begin{array}{c}\text { Después } \\
\begin{array}{c}n=22 \\
n(\%)\end{array}\end{array}$ & p & $\begin{array}{c}\text { Antes } \\
n=32 \\
n(\%)\end{array}$ & $\begin{array}{c}\text { Después } \\
n=29 \\
n(\%)\end{array}$ & $p$ & $\begin{array}{c}\text { Antes } \\
n=102 \\
n(\%)\end{array}$ & $\begin{array}{c}\text { Después } \\
\text { n = } 101 \\
n(\%)\end{array}$ & $p$ \\
\hline Prescripción inadecuada & $32(100 \%)$ & 37 (74\%) & * & $38(100 \%)$ & $6(27,3 \%)$ & * & $15(46,9 \%)$ & $12(41,4 \%)$ & 0,39 & $85(83,3 \%)$ & $55(54,5 \%)$ & $<0,05$ \\
\hline \multicolumn{13}{|l|}{ Indicadores } \\
\hline Indicación inadecuada & $32(100 \%)$ & $37(74 \%)$ & * & $38(100 \%)$ & $4(18,2 \%)$ & * & $5(15,6 \%)$ & $9(31 \%)$ & 0,01 & $75(73,5 \%)$ & $50(49,5 \%)$ & $<0,05$ \\
\hline Dosis inadecuada & $2(6,3 \%)$ & $4(8 \%)$ & 0,66 & $7(18,4 \%)$ & $1(4,5 \%)$ & 0,004 & $2(6,3 \%)$ & $1(3,4 \%)$ & 0,50 & $11(10,8 \%)$ & $6(5,9 \%)$ & 0,21 \\
\hline Intervalo inadecuado & $5(15,6 \%)$ & $6(12 \%)$ & 0,42 & $7(18,4 \%)$ & $1(4,5 \%)$ & 0,004 & $5(15,6 \%)$ & $4(13,8 \%)$ & 0,69 & $17(16,7 \%)$ & $11(10,9 \%)$ & 0,23 \\
\hline Duración inadecuada & $6(18,8 \%)$ & $5(10 \%)$ & 0,07 & $18(47,4 \%)$ & $2(9,1 \%)$ & $<0,05$ & $9(28,1 \%)$ & $3(10,3 \%)$ & 0,001 & $33(32,4 \%)$ & $10(9,9 \%)$ & $<0,05$ \\
\hline $\begin{array}{l}\text { Promedio días } \\
\text { hospitalizado } \pm D^{* *}\end{array}$ & $12,6 \pm 9,5$ & $8,2 \pm 7,4$ & 0,02 & $25,8 \pm 56,3$ & $9,5 \pm 6$ & 0,18 & $20,2 \pm 29,4$ & $9,5 \pm 7,6$ & 0,06 & $19,8 \pm 38,5$ & $8,87 \pm 7,2$ & 0,005 \\
\hline Cura clínica & $27(84,4 \%)$ & $42(84 \%)$ & 1 & $26(68,4 \%)$ & $15(68,2 \%)$ & 1 & $25(78,1 \%)$ & $24(82,8 \%)$ & 0,37 & $78(76,5 \%)$ & $81(80,2 \%)$ & 0,52 \\
\hline \multicolumn{13}{|l|}{ Esquema de tratamiento } \\
\hline Monoterapia & $1(3,1 \%)$ & $11(22 \%)$ & & $8(21,1 \%)$ & $14(63,6 \%)$ & & $25(78,1 \%)$ & $22(75,9 \%)$ & & $34(33,3 \%)$ & $47(46,5 \%)$ & \\
\hline Terapia combinada & $31(96,9 \%)$ & $39(78 \%)$ & $<0,05$ & $30(78,9 \%)$ & $8(36,4 \%)$ & $<0,05$ & $7(21,9 \%)$ & $7(24,1 \%)$ & 0,74 & $68(66,7 \%)$ & $54(53,5 \%)$ & 0,06 \\
\hline $\begin{array}{l}\text { Promedio días de } \\
\text { tratamiento } A M \pm D E^{* *}\end{array}$ & $11,9 \pm 6,9$ & $9,5 \pm 6,6$ & 0,12 & $10 \pm 4,5$ & $8,91 \pm 3,8$ & 0,36 & $9,5 \pm 4,5$ & $10 \pm 6,5$ & 0,69 & $10,4 \pm 5,4$ & $9,5 \pm 6$ & 0,27 \\
\hline
\end{tabular}


antes de la difusión de las RU 79\% de los pacientes recibieron terapia combinada, reduciéndose a $36 \%$ postintervención (Tabla 3).

Sólo tres pacientes con infecciones de foco sistema nervioso central fueron incluidos en el estudio, uno en el grupo pre intervención y dos en el post intervención; por ende, no es posible obtener diferencias significativas al respecto.

\section{Comparación de la cantidad de AMs utilizados antes y después de la implementación de las $R U$}

Con la implementación de las RU se observaron cambios estadísticamente significativos en los consumos de ampicilina/sulbactam y amikacina. El consumo de ampicilina/sulbactam aumentó en 507\%, de 1,01 a 6,13 DDD/100 camas/día, mientras que para amikacina, el incremento fue de $92 \%$, desde 1,24 a $2,38 \mathrm{DDD} / 100$ camas/día pre y post-intervención, respectivamente.

Con posterioridad a la intervención, se observó un aumento del uso de ciprofloxacina (de 2,55 a 3,24 DDD/100 camas/día, equivalente a $27 \%$ de incremento), siendo éste principalmente en su presentación oral: ciprofloxacina oral aumentó su consumo de 1,7 a 2,46 DDD/100 camas/ día, mientras que su presentación endovenosa disminuyó de 0,86 a 0,79 DDD/100 camas/día luego de la implementación de las RU.

Por otra parte, se observó una disminución en el uso de ceftriaxona (de 8,34 a 7,53 DDD/100 camas/día, equivalente a $9,7 \%$ de reducción) y de levofloxacina (de 1,46 a $0,63 \mathrm{DDD} / 100$ camas/día, equivalente a $57 \%$ de reducción). En cuanto a claritromicina, agregada al arsenal terapéutico del hospital después de la intervención, se registró un consumo total de 0,24 DDD/100 camas/día. (Figura 4).

\section{Discusión}

El conjunto de NAC, ITU e IAA son patologías infecciosas adquiridas en la comunidad, donde el consumo de ceftriaxona y $\mathrm{FQ}$, AMs relacionados en mayor medida con selección de cepas e infecciones por $C$. difficile, son altamente utilizados ${ }^{21}$. El presente trabajo buscó reemplazar esta clase de AMs por esquemas igualmente efectivos, pero con menor impacto ecológico.

Nuestra experiencia, fue la primera realizada en Chile de este tipo y demostró, al igual que otros estudios internacionales, que intervenciones que buscan mejorar las prescripciones de AMs, son efectivas ${ }^{46}$. Nuestros resultados evidenciaron que por medio de las RU implementadas se logró disminuir en $35 \%$ las prescripciones inadecuadas de AMs.

Tanto las indicaciones como las duraciones inadecuadas presentaron una disminución significativa luego de

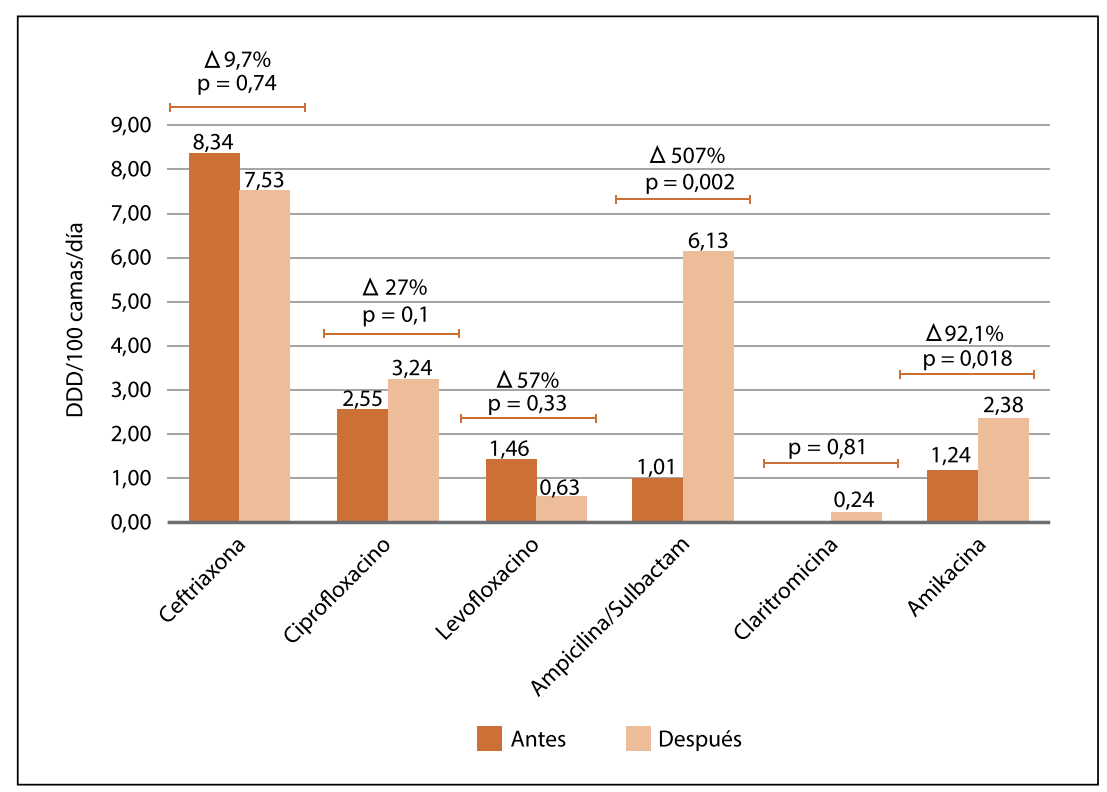

Figura 4. Consumo de antimicrobianos estudiados en DDD/100 camas/día antes y después de la difusión de las recomendaciones de uso. $\Delta$ : Variación con respecto al porcentaje basal.

la implementación de las RU, lo que interpretamos como que los médicos tratantes se ajustaron a las sugerencias realizadas, prefiriendo esquemas AMs con menor impacto ecológico y acotando los días de antibioterapia.

El 100\% de los esquemas indicados para tratar NAC previo a la intervención, para efectos de nuestro trabajo, fueron inadecuados, es decir a todos los pacientes se les indicaron esquemas distintos a ampicilina/sulbactam asociado o no a claritromicina (esquema sugerido en las RU dependiendo de la gravedad), prefiriendo el esquema habitual de ceftriaxona asociado a levofloxacina. Posteriormente a la intervención, cerca de $73 \%$ de los esquemas dirigidos al foco respiratorio se ajustaron a las RU.

Esto se correlaciona con los resultados buscados y obtenidos en nuestro trabajo, de disminuir el consumo de levofloxacina y ceftriaxona; sin embargo, en ningunos de los dos AMs, la disminución en el consumo fue estadísticamente significativa. Lo observado pudo deberse, en primer lugar, al corto tiempo considerado para evaluar el efecto de las RU en el consumo (un mes aproximadamente), no logrando detectar una disminución importante, ya fuese por falta de difusión de los nuevos esquemas o por la alta rotación de médicos que existe en nuestro hospital por ser un centro formador universitario. Por otra parte, la estacionalidad de las infecciones respiratorias puede haber interferido en nuestros resultados; a pesar de que se buscó anularla, no fue posible hacerlo con total certeza.

Otro elemento a considerar en la falta de significancia estadística en la disminución del consumo de ceftriaxona fue su uso esencialmente en las IIA, donde nuestra 
sugerencia fue reemplazarla por ampicilina/sulbactam; no obstante, sólo se logró disminuir las prescripciones inadecuadas en $26 \%$, permaneciendo como terapia de elección la cefalosporina asociada a metronidazol. Esta recomendación no fue aceptada en su totalidad por falta de información microbiológica al respecto ya que, según nuestra búsqueda, no existían trabajos que informaran la susceptibilidad de las bacterias responsables de IIA de la comunidad, lo que generó desconfianza en los médicos tratantes.

Es importante destacar, al menos en el foco respiratorio, la aceptación y adherencia de los tratantes a los nuevos esquemas sugeridos, sin observarse cambios en la cura clínica de los pacientes antes y después de la intervención, pues los esquemas sugeridos para el tratamiento de NAC fueron igualmente efectivos. Esto no ocurrió en el foco abdominal, en cuya condición sólo se lograron disminuir las indicaciones inadecuadas de 100 a 74\%, debiéndose esencialmente a lo mencionado con anterioridad: falta de información microbiológica al respecto.

En el foco genito-urinario, las prescripciones inadecuadas aumentaron de 15,6 a $31 \%$; esto se puede atribuir a la mayor utilización de ciprofloxacina post-intervención, lo que se consideró inadecuado según nuestras RU, dado que al analizar los pacientes a quienes se les indicó ciprofloxacina, no presentaban factores de riesgo para presentar toxicidad con amikacina (falla renal, adulto mayor, deshidratación, etc) y el aminoglucósido debió ser el AM de elección; sin embargo, el temor de los tratantes a la toxicidad de los aminoglucósidos parece ser el principal factor influyente, aunque está bien documentado en la literatura médica que el uso de esta clase de AM en monodosis diaria es igualmente efectivo y seguro que otros tratamientos. No obstante, ciprofloxacina fue indicada, en su mayoría en su presentación oral, lo que podría justificarse por el rápido cambio a terapia oral que se promovió durante la intervención. Su utilización fue considerada inadecuada sólo en los casos en que se prefirió la FQ a pesar de que el agente aislado en el urocultivo también era sensible a cotrimoxazol y el paciente no tenía contraindicación de recibirlo. Cotrimoxazol se recomendó como AM de elección durante la intervención para switch a terapia oral, por sobre ciprofloxacina, dado su menor impacto en la selección de cepas resistentes.

La curación clínica de los pacientes no varió significativamente en el grupo pre y post-intervención en ninguno de los focos. La mayor aceptación de las RU fue observada en el tratamiento de foco respiratorio; sin embargo, ni en el IIA ni el urinario se evidenciaron cambios en el porcentaje de curación clínica; podría decirse al respecto que el principal efecto de nuestra intervención iba enfocado en el impacto ecológico a largo plazo, ofreciendo terapias igualmente efectivas, pero con menor inducción de resistencia.
Por efectos de tiempo no se pudo medir cambios en las susceptibilidades in vitro luego de la intervención, pero claramente es un factor a considerar en futuras investigaciones y habría sido de gran relevancia en nuestros resultados.

El otro indicador que experimentó cambios significativos luego de la intervención fue la duración inadecuada, siendo, nuevamente el foco respiratorio donde mayor cambio se produjo, con una tendencia a menores días de tratamiento AM, pero sin alcanzar significación estadística. Las recomendaciones son acortar los días de tratamiento AM lo más posible, disminuyendo así la presión selectiva ejercida sobre las bacterias, reduciendo el riesgo de efectos adversos por medicamentos y los costos asociados a la hospitalización; nos parece importante seguir incentivando a los tratantes a indicar terapias acortadas y realizar el cambio precoz a terapia oral ${ }^{47}$. Un ejemplo de ello se observó en el manejo de las IIA, en las que se obtuvo una disminución, no significativa, de 11,9 a 9,5 los días de tratamiento AM. Recientemente se publicó un estudio para IIA que demostró que cursos cortos de cuatro días de tratamiento AM parecen ser igualmente efectivos que terapias más prolongadas (ocho días) ${ }^{47}$, ya que la remoción del foco infeccioso quirúrgicamente es la principal intervención que permite la cura de los pacientes $^{47-49}$.

Previo a la intervención, las indicaciones eran principalmente terapias combinadas, esencialmente para IIA y respiratorias, que, en la práctica habitual de este centro correspondían a ceftriaxona o ciprofloxacina con metronidazol y ceftriaxona con levofloxacina, respectivamente. Con posterioridad a la intervención se observó que, en infecciones de foco respiratorio, los tratantes prefirieron la monoterapia. Durante la difusión de las RU, se promovió el cambio temprano a terapia oral y se enfatizó en preferir la monoterapia ya que la frecuencia de aislamiento de agentes atípicos causante de NAC en Chile es inferior a las tasas observadas en E.U.A. ${ }^{50}$. Cabe destacar que recientemente se publicó un trabajo en pacientes con NAC hospitalizados en salas no críticas, que demostró la ausencia de diferencias estadísticamente significativas en mortalidad a 90 días, entre tratamiento con $\beta$-lactámicos en monoterapia y asociarlos con AMs que ofrezcan cobertura sobre agentes atípicos (FQ o macrólidos $)^{51}$.

Durante el período post-intervención se pudo apreciar un aumento significativo de la utilización de monoterapia en el manejo de IIA; no obstante, no superó la terapia combinada. Una probable explicación puede ser atribuida a que, en servicios quirúrgicos, donde se concentran los pacientes con IIA, la difusión de las RU no tuvo mayor acogida, como se mencionó anteriormente, por lo que el cambio de ceftriaxona metronidazol a ampicilina/ sulbactam no fue lo esperado. 
El uso de la monoterapia en el manejo de ITU fue de elección antes y después de la intervención. Esto concuerda con la literatura médica sobre la baja utilidad de usar terapias asociadas en el tratamiento de ITU ${ }^{34,35,52}$. Un bajo porcentaje de terapias combinadas con amikacina y ceftriaxona en sospecha de sepsis urinarias se debió a que los aminoglucósidos poseen excelente actividad en sangre y orina, además de potenciar los efectos del $\beta$-lactámico, principalmente frente a bacterias gramnegativas ${ }^{53,54}$.

En el grupo analizado previo a la implementación de las RU, el principal foco de infección fue pulmonar, a diferencia del grupo post intervención donde el foco abdominal fue el más frecuente; ambas poblaciones no fueron homogéneas, lo que pudo incidir directamente en nuestros resultados. Esta diferencia puede deberse a que durante el período en que se ingresaron pacientes luego de la intervención (diciembre de 2014 a mayo de 2015), las tasas de virus respiratorios, que en general co-infectan con bacterias $^{50}$, fue menor que durante el período I (abril a septiembre de 2014) $)^{55}$, lo que podría haber provocado la disminución en el número de consultas y hospitalizaciones por infecciones respiratorias.

De los 206 pacientes incluidos en ambos grupos, sólo se ingresaron tres con foco infeccioso en el sistema nervioso central, representando menos de $2 \%$ de la muestra, lo que no permite extraer conclusiones en este subgrupo de pacientes.

$\mathrm{Al}$ analizar el efecto de las RU en el consumo de AMs, se observó que ceftriaxona fue el AM más consumido. Este fenómeno ha sido descrito en múltiples trabajos chilenos e internacionales a nivel hospitalario, confirmando que las cefalosporinas en general, debido a su amplio espectro y excelente perfil de seguridad, son ampliamente utilizadas ${ }^{10,24-26}$.

Con la implementación de las RU se observó, una disminución no significativa del uso de ceftriaxona y levofloxacina. Ambos AMs se prescribían como tratamiento de elección en NAC, los que fueron reemplazados por ampicilina/sulbactam y claritromicina, respectivamente. Para el caso de claritromicina, solo se observó consumo post-intervención, ya que previo a la implementación de las RU no era parte del arsenal terapéutico del centro asistencial; sin embargo, no fue tan marcado el consumo, dado que en el grupo post-intervención, predominó el foco abdominal.

Los aminoglucósidos, que se sugirieron como de elección de ITU, en aquellos pacientes sin factores de riesgo para toxicidad, se utilizaron en mayor proporción luego de la intervención.

Ampicilina/sulbactam registró un aumento significativo de su consumo luego de la implementación de las RU, esto debido a que se les recomendaba como tratamiento de elección para NAC e IIA. Con la difusión de las RU, representó una alternativa más ecológica que da cobertura sobre los tres principales agentes etiológicos de NAC, además de bacterias anaerobias en IIA $^{56}$.

A partir de los resultados obtenidos, podemos decir que el éxito de intervenciones como la desarrollada en la presente investigación, depende principalmente de la difusión de las RU elaboradas, ya que permite socializar las sugerencias, discutirlas, conocer la evidencia en la cual están basadas y la opinión, tanto de los creadores como de quienes las llevarán a cabo. Basándose en este concepto, el proceso de difusión desarrollado en este trabajo se dirigió principalmente en tres sectores: el Servicio de Urgencias, donde se inicia gran parte de los tratamientos empíricos de enfermedades infecciosas adquiridas en la comunidad; en el Departamento de Medicina y UPC, donde se encuentra la mayoría de los pacientes con patologías incluidas en las RU; y los médicos en formación, tanto internos de medicina como residentes de especialidades u sub-especialidades.

A pesar de los esfuerzos realizados, no se consiguió una difusión homogénea de las RU en todo el establecimiento, principalmente por disposición de tiempos y acogida de la intervención, lo que podría haber afectado los resultados. Parece importante para este tipo de estudios contar con períodos más prolongados de difusión, además de un constante refuerzo de modo de mantener los cambios en los tratamientos AMs propuestos.

El presente trabajo tiene algunas limitaciones, como el haber sido realizado en un solo centro, lo que podría afectar su validez externa. Además, el tamaño de la muestra, a pesar de ser adecuado según el cálculo, fue reducido lo que podría afectar la representatividad de los pacientes con infecciones adquiridas en la comunidad.

Por otra parte, es importante mencionar que no se realizó un cálculo de tamaño de muestra específico por patología infecciosa (subgrupos), lo que también puede haber afectado los resultados, en cuanto a la homogeneidad de la muestra (pre y post-intervención) y la no significancia estadística en algunos parámetros, dado el n reducido. No obstante, nuestro principal objetivo fue evaluar el seguimiento de las RU por los médicos tratantes, independiente de la patología infecciosa diagnosticada.

Con respecto al diseño del trabajo, los pacientes enrolados no cumplieron con criterios establecidos para el diagnóstico, sino más bien el diagnóstico fue realizado individualmente por el médico tratante, lo que pudo sesgar la muestra. No obstante, ningún participante del grupo creador de las RU tuvo injerencia en las elecciones de los tratamientos.

Otro factor importante que puede haber afectados nuestros resultados fue el corto período de comparación para el cálculo de las DDD. Esto se debió esencialmente a problemas logísticos y de tiempo que tuvo el equipo investigador; nos parece importante medir los efectos en tiempos más prolongados. 
El diseño del proyecto, antes y después, tiene desventajas en comparación con el ensayo clínico controlado aleatorizado de muestras paralelas; por lo tanto, es posible que no se pueda establecer la importancia relativa de la intervención en la modificación de las prácticas de prescripción. Para lograr que la intervención y sus resultados perduren en el tiempo y queden incluidas dentro de la práctica habitual del establecimiento, se deberá implementar otras estrategias como una mejor y constante difusión de las RU y analizar la posible utilidad de ciclado o heterogeneidad de AMs que, según la evidencia sería la mejor estrategia para disminuir la resistencia bacteriana ${ }^{57,58}$.

Intervenciones que buscan racionalizar el uso de los AMs tienen como principal beneficio una mejoría en la susceptibilidad bacteriana, por lo que será interesante medir a largo plazo los efectos de las RU implementadas en la microbiota del establecimiento, como también el evaluar la efectividad y los costos asociados a los nuevos esquemas AMs propuestos durante períodos más prolongados de tiempo.

\section{Conclusiones}

Las medidas de intervención implementadas permitieron evaluar el efecto de RU basadas en la evidencia científica disponible y en la susceptibilidad bacteriana nacional y del propio establecimiento, en la disminución de prescripciones inadecuadas de ceftriaxona y levofloxacina. Se logró disminuir significativamente la proporción de prescripciones inadecuadas de AMs, obteniéndose el efecto más notorio en lo referente a la indicación y la duración de las terapias.

A pesar de que no fue unos de los objetivos principales de nuestro trabajo, es importante destacar la disminución en la estadía hospitalaria de los pacientes post-intervención. Este hallazgo sirve como aliciente para futuros nuevos estudios que aborden específicamente este punto.

La intervención logró disminuir la utilización de aquellos AMs que se asocian en mayor medida con la resistencia bacteriana como lo son ceftriaxona y levofloxacina, y aumentar el uso de medicamentos considerados más ecológicos.
La difusión de las RU fue uno de los factores fundamentales para lograr los objetivos del estudio. Para implementar las intervenciones desarrolladas es necesario que sean consensuadas por todos los que participan en la farmacoterapia de los pacientes, logrando una intervención persuasiva más que restrictiva, las que tienen mayor aceptación.

Luego de la realización de este trabajo queda la inquietud para que futuras iniciativas de investigación midan el efecto en la resistencia bacteriana a largo plazo, analizar los costos asociados a este tipo de intervenciones, como también el promover esfuerzos por mejorar el uso de los AMs de primera línea.

\section{Resumen}

Introducción: Actualmente cerca de la mitad de las prescripciones de antimicrobianos son inadecuadas, lo que aumenta la resistencia bacteriana. Tanto cefalosporinas como fluoroquinolonas se asocian con este fenómeno: aumento de bacterias productoras de $\beta$-lactamasas e infecciones por Clostridioides difficile, por lo que las agencias reguladoras buscan racionalizar su uso. Objetivo: Evaluar el efecto de recomendaciones para el uso adecuado de antimicrobianos en la proporción de prescripciones inadecuadas de ceftriaxona y fluoroquinolonas. Metodología: Se desarrolló un estudio de antes y después, prospectivo e intervencional, que comparó la calidad y la cantidad de uso de ceftriaxona y fluoroquinolonas antes y después de la implementación de recomendaciones de uso para tratamientos de enfermedades infecciosas adquiridas en la comunidad. Los parámetros medidos fueron: proporción de prescripciones inadecuadas y DDD. Los datos se analizaron por medio del test de $\chi^{2}$, corrección de Fisher y test de Student. Resultados: Se evaluaron 206 pacientes, observándose una disminución de $35 \%$ en las prescripciones inadecuadas, una reducción del consumo de ceftriaxona y levofloxacina y un aumento significativo de la utilización de ampicilina/sulbactam. Conclusiones: La implementación de recomendaciones de uso basadas en evidencia científica y susceptibilidad local, permitieron disminuir la proporción de prescripciones inadecuadas y reducir el consumo de ceftriaxona y fluoroquinolonas.

\section{Referencias bibliográficas}

1.- Guanche H, Pisonero J J. Programa de control de antibióticos en instituciones de salud. Rev Cuba Cirugía 2011; 50 (3): 401-12. http:// scielo.sld.cu/pdf/cir/v50n3/cir17311.pdf

2.- Nigam A, Gupta D, Sharma A. Treatment of infectious disease: Beyond antibiotics. Microbiol Res 2014; 169 (9-10): 643-51. doi: 10.1016/j.micres.2014.02.009

3.- John J F, Fishman N. Programmatic role of the infectious diseases physician in controlling antimicrobial costs in the hospital. Clin Infect Dis 1997; 24: 47185. https://academic.oup.com/cid/articlepdf/24/3/471/1188586/24-3-471.pdf

4.- Willemsen I, Groenhuijzen A, Bogaers D, Stuurman A, van Keulen P, Kluytmans J.
Appropriateness of antimicrobial therapy measured by repeated prevalence surveys. Antimicrob Agents Chemother 2007; 51 (3): 864-7. DOI: 10.1128/AAC.00994-06.

5.- Fleming-Dutra K, Hersh A, Shapiro D, Bartoces M, Enns E, File T, et al.

Prevalence of inappropiate antibiotic prescriptions among US ambulatory care visits, 2010-2011. J Am Med Assoc 
2016; 315 (17): 1864-73. doi: 10.1001/ jama.2016.4151

6.- World Health Organization. WHO Global Strategy for Containment of Antimicrobial Resistance [Internet]. 2001. Disponible en: http://www.who.int/csr/resources/publications/ drugresist/WHO_CDS_CSR_DRS_2001_2_ EN/en/

7.- Cabrera S, Sosa L, Arteta Z, Seija V, Mateos S, Perna A, et al. Uso racional de antimicrobianos en el departamento de medicina interna de un hospital universitario: resultados de una experiencia piloto. Rev Chilena Infectol 2012; 29 (1): 7-13. http://dx.doi.org/10.4067/S071610182012000100001

8.- Livermore D M. Bacterial resistance: origins, epidemiology and impact. Clin Infect Dis 2003; 36 (Suppl 1): 11-23. DOI:10.1086/344654.

9.- Ashiru-Oredope D, Sharland M, Charani E, McNulty C, Cooke J. Improving the quality of antibiotic prescribing in the NHS by developing a new Antimicrobial Stewardship Programme: Start Smart-Then Focus. J Antimicrob Chemother. 2012 Julio; 67 Suppl 1: 51-63. DOI: $10.1093 / \mathrm{jac} / \mathrm{dks} 20$.

10.- Ávila F. Consumo de antibióticos de uso restringido y semi-restringido en un hospital público de alta complejidad. Tesis para optar al título de Químico Farmacéutico. Universidad de Chile; 2012.

11.- Gottesman B S, Carmeli Y, Shitrit P, Chowers $M$. Impact of quinolone restriction on resistance patterns of Escherichia coli isolated from urine by culture in a community setting. Clin Infect Dis 2009; 49: 869-75. doi: 10.1086/605530.

12.- Goldstein R C, Husk G, Jodlowski T, Mildvan D, Perlman D C, Ruhe J J. Fluoroquinoloneand ceftriaxone-based therapy of communityacquired pneumonia in hospitalized patients: the risk of subsequent isolation of multidrugresistant organisms. Am J Infect Control 2014; 42 (5): 539-41. doi: 10.1016/j.ajic.2014.01.005.

13.- Polk R, Johnson C, McClish D, Wenzel R, Edmond M. Predicting hospital rates of fluoroquinolone-resistant Pseudomonas aeruginosa from fluoroquinolone use in US hospitals and their surrounding communities. Clin Infect Dis 2004; 39 (4): 497-503. DOI: $10.1086 / 42264$.

14.- Kee V. Clostridium difficile infections in older adults: a review and uptodate on its managements. Am J Geriatr Pharm 2012; 10 (1): 14-24. doi: 10.1016/j. amjopharm.2011.12.004.

15.- Magill S S, Edwards J R, Bamberg W, Beldavs Z G, Dumyati G, Kainer M A, et al. Multistate point-prevalence survey of health care-associated infections. N Engl J Med 2014; 370 (13): 1198-208. doi: 10.1056/ NEJMoa1306801.

16.- Gardilcic M, Fica A, Chang M, Llanos C, Luzoro A. Diarrea asociada a Clostridium difficile en un hospital de adultos . Estudio descriptivo. Rev Chilena Infectol 2000; 17 (4): 307-12. https://scielo.conicyt.cl/pdf/rci/v17n4/ art05.pdf.

17.- Herrera P, Cotera A, Fica A, Galdo T, Alvo M. Alta incidencia de diarrea por Clostridium difficile en pacientes nefrológicos. Rev Med Chile 2003; 131 (4) 397-403. http://dx.doi.org/10.4067/S003498872003000400007.

18.- Pakyz A, Carroll N V, Harpe S E, Oinonen M, Polk R E. Economic impact of Clostridium difficile infection in a multihospital cohort of academic health centers. Pharmacother 2011; 31 (6): 546-51. doi: 10.1592/phco.31.6.546.

19.- Schwaber M J, Navon-Venezia S, Kaye K S, Ben-ami R, Schwartz D, Carmeli Y. Clinical and Economic Impact of Bacteremia with Extended-Spectrum- $\beta$-lactamaseProducing Enterobacteriaceae. Antimicrob Agents Chemother 2006; 50 (4): 1257-62. DOI: 10.1128/AAC.50.4.1257-1262.2006.

20.- Paterson D. "Collateral Damage" from Cephalosporin or Quinolone Antibiotic Therapy. Clin Infect Dis 2004; 38 (Suppl 4): 341-5. https://doi.org/10.1086/382690.

21.- Chalmers J, Al-Khairalla M, Short P, Fardon T, Winter J. Proposed changes to management of lower respiratory tract infections in response to the Clostridium difficile epidemic. J Antimicrob Chemother 2010; 65 (4): 608-18. doi: 10.1093/ $\mathrm{jac} / \mathrm{dkq} 038$.

22.- Cabrera S, Sosa L, Arteta Z, Seija V, Mateos S, Perna A, et al. Uso racional de antimicrobianos en el departamento de medicina interna de un hospital universitario: resultados de una experiencia piloto. Rev Chilena Infectol 2012; 29 (1): 7-13. http://dx.doi.org/10.4067/S071610182012000100001

23.- Fica C A, Cabello M A, Juliet L C, Prado D P, Bavestrello F L. Consumo de antimicrobianos parenterales en diferentes hospitales de Chile durante el año 2005. Rev Chilena Infectol 2008; 25 (6): 419-27. http://dx.doi.org/10.4067/ S0716-10182008000600001.

24.- Hosoglu S, Esen S, Ozturk R, Altindis M, Ertek M, Kaygussuz S, et al. The effect of a restriction policy on the antimicrobial consumption in Turkey: a country-wide study. Eur J Clin Pharmacol 2005; 61 (10): 727-31. DOI: $10.1007 / \mathrm{s} 00228-005-0968-8$.

25.- Cook P P, Catrou P G, Christie J D. Reduction in broad-spectrum antimicrobial use associated with no improvement in hospital antibiogram. J Antimicrob Chemother 2004; 53: 853-9. DOI: $10.1093 / \mathrm{jac} / \mathrm{dkh} 163$.

26.- Weinberger M, Sweet S, Leibovici L, Pitlik S, Samra Z. Correlation between candiduria and departmental antibiotic use. J Hosp Infect 2003; 53: 183-6. PMID: 12623318.

27.- Cabrera S. Uso racional y responsable de los antimicrobianos. Arch Med Interna 2009; 31
(1): 74-80. http://www.scielo.edu.uy/pdf/ami/ v31n2-3/v31n2-3a06.pdf.

28.- Pisonero J J, Guanche H, Mir Narbona I, Enseñat Sánchez R, Fiterre Lancis I, García Arzola B. Implementación de un programa de control de antibióticos a nivel hospitalario: efecto económico. Rev Cuba Cirugía 2014; 53 (1): 52-9. http://scielo.sld.cu/pdf/cir/v53n1/ cir06114.pdf.

29.- Meyer E, Buttler J, Schneider C, Strehl E, Schroeren-Boersch B, Gastmeier P, et al. Modified guidelines impact on antibiotic use and costs: duration of treatment for pneumonia in a neurosurgical ICU is reduced. J Antimicrob Chemother 2007; 59: 1148-54. DOI: 10.1093/ $\mathrm{jac} / \mathrm{dkm} 088$.

30.- Hatler CW, Mast D, Corderella J, Mitchell G, Howard K, Aragon J, et al. Using evidence and process improvement strategies to enhance healthcare outcomes for the critically ill: a pilot project. Am J Crit Care 2006; 15 (6): 546-55. PMID: 17053262.

31.- Ramakrishnan K, Scheid D C. Diagnosis and management of acute pyelonephritis in adults. Am Fam Physician 2005; 71 (5): 933-42. PMID: 15768623

32.- Sartelli M, Viale P, Catena F, Ansaloni L, Moore E, Malangoni M, et al. 2013 WSES guidelines for management of intra-abdominal infections. World J Emerg Surg [Internet] 2013; 8 (1): 3-29. doi: 10.1186/1749-7922-8-3.

33.- Tellado J M, Barcenilla F, Palomar M, Serrano R, Moya M, Mensa J. Consenso Pautas de tratamiento antibiótico empírico de las infecciones intraabdominales. Rev Esp Quimioter 2005; 18 (2): 179-86. https://seq.es/ wp-content/uploads/2008/08/179.pdf.

34.- Chair M G, Bartoletti R, Bjerklund T E, Johansen T, Cai (Guidelines Associate), Çek M, Köves B (Guidelines Associate), et al. Guidelines on urological infections. Eur Assoc Urol. 2015. https://uroweb.org/wp-content/ uploads/19-Urological-infections_LR2.pdf

35.- Gupta K, Hooton T M, Naber K G, Wullt B, Colgan R, Miller L G, et al. International clinical practice guidelines for the treatment of acute uncomplicated cystitis and pyelonephritis in women: A 2010 update by the Infectious Diseases Society of America and the European Society for Microbiology and Infectious Diseases. Clin Infect Dis 2011; 52 (5): e103-20. doi: $10.1093 / \mathrm{cid} / \mathrm{ciq} 257$.

36.- Tunkel A R, Hartman B J, Kaplan S L, Kaufman B A, Roos K L, Scheld W M, et al. Practice guidelines for the management of bacterial meningitis. Clin Infect Dis 2004; 39: 1267-84. DOI: $10.1086 / 425368$

37.- Solomkin J S, Mazuski J E, Bradley J S, Rodvold K A, Goldstein E J C, Baron E J, et al. Diagnosis and management of complicated intra-abdominal infection in adults and children: guidelines by the Surgical Infection 
Society and the Infectious Diseases Society of America. Clin Infect Dis. 2010; 50 (2): 133-64. DOI: $10.1086 / 649554$.

38.- Society A T. Guidelines for the management of adults with community-acquired pneumonia. Am J Respir Crit Care Med 2001; 163: 173054. DOI: 10.1164/ajrccm.163.7.at1010.

39.- Lim W S, Baudouin S V, George R C, Hill A $\mathrm{T}$, Jamieson C, Le Jeune I, British Thoracic Society. Guidelines for the management of community acquired pneumonia in adults: update 2009. Thorax. 2009; 64 Suppl iii: ii1ii55. doi:10.1136/thx.2009.121434.

40.- Ministerio de Salud de Chile. Guía Clínica AUGE. Neumonía adquirida en la comunidad en adultos de 65 años y más. 2011. Disponible en: http://web.minsal.cl/portal/url/item/7220fdc 4341744a9e04001011f0113b9.pdf.

41.- Bamberger D M. Diagnosis, initial management, and prevention of meningitis. Am Fam Physician 2010; 82 (12): 1491-8. https:// www.aafp.org/afp/2010/1215/p1491.pdf.

42.- Chaudhuri A, Martin P M, Kennedy P G E, Seaton R A, Portegies P, Bojar M, et al. EFNS guideline on the management of communityacquired bacterial meningitis: report of an EFNS task force on acute bacterial meningitis in older children and adults. Eur J Neurol 2008; 15: 649-59. doi: 10.1111/j.14681331.2008.02193.x.

43.- Guirao X, Arias J, Badía J, García-Rodríguez J, Mensa J, F Á-L, et al. Recomendaciones en el tratamiento antibiótico empírico de la infección intraabdominal. Rev Esp Quim 2009; 22 (3): 151-72. PMID: 19662549.

44.- Mandell L A, Wunderink R G, Anzueto A, Bartlett J G, Campbell G D, Dean N C, et al. Infectious Diseases Society of America/ American Thoracic Society consensus guidelines on the management of community- acquired pneumonia in adults. Clin Infect Dis 2007; 44 (Suppl 2): S27-72. DOI: 10.1086/511159.

45.- Bantar C, Curcio D, Jasovich A, Bagnulo H, Arango Á, Bavestrello L, et al. Neumonía aguda adquirida en la comunidad en adultos: Actualización de los lineamientos para el tratamiento antimicrobiano inicial basado en la evidencia local del Grupo de Trabajo de Sudamérica (ConsenSur II). Rev Chilena Infectol 2010; 27 (Supl 1): 9-38. http://dx.doi. org/10.4067/S0716-10182010000400002.

46.- Guanche Garcell H, Pisonero Socias J J, Enseñat Sánchez R, Fiterre Lancis I, Mir Narbona I, et al. Impacto de un programa de control de la calidad de la prescripción de antibióticos en un hospital de La Habana, Cuba. Rev Panam Salud Pública 2011; 30 (6): 598-602. http://www.scielosp.org/ scielo.php?script $=$ sci_arttext\&pid $=\mathrm{S} 1020$ 49892011001200017\&lng=es\&nrm=iso\&tlng= es.

47.- Sawyer R G, Claridge J A, Nathens A B, Rotstein O D, Duane T M, Evans H L, et al. Trial of short-course antimicrobial therapy for intraabdominal infection. $\mathrm{N}$ Engl J Med 2015; 372 (21): 1996-2005. doi: 10.1056/ NEJMoa1411162.

48.- Bosscha K, van Vroonhoven T J, van der Werken C. Surgical management of severe secondary peritonitis. Br J Surg 1999; 86 (11): 1371-7. DOI: $10.1046 / j .1365-$ 2168.1999.01258.x.

49.- Schein M, Assalia A, Bachus H. Minimal antibiotic therapy after emergency abdominal surgery: a prospective study. Br J Surg 1994; 81 (7): 989-91. PMID: 7922094.

50.- Luchsinger V, Ruiz M, Zunino E, Martínez M, Machado C, Piedra P A, et al. Communityacquired pneumonia in Chile: the clinical relevance in the detection of viruses and atypical bacteria. Thorax. 2013; 68: 1000-6. doi: 10.1136/thoraxjnl-2013-203551.

51.- Postma D F, van Werkhoven C H, van Elden L J, Thijsen S F, Hoepelman A I, Kluytmans $\mathrm{J} A$, et al. Antibiotic treatment strategies for community-acquired pneumonia in adults N Engl J Med 2015; 372 (14): 1312-23. doi: 10.1056/NEJMoa1406330.

52.- Warren J W, Abrutyn E, Hebel J R, Johnson J R, Schaeffer A J, Stamm W E. Guidelines for antimicrobial treatment of uncomplicated acute bacterial cystitis and acute pyelonephritis in women. Clin Infect Dis 1999; 29: 745-58. DOI: $10.1086 / 520427$.

53.- Giamarellou H. Aminoglycosides plus betalactams against gram-negative organisms. Evaluation of in vitro synergy and chemical interactions. Am J Med. 1986; 80: 126-37. PMID: 3088998.

54.- Leibovici L, Vidal L, Paul M. Aminoglycoside drugs in clinical practice: an evidence-based approach. J Antimicrob Chemother. 2009; 63 (2): 246-51. doi: 10.1093/jac/dkn469.

55.- Sociedad Chilena de Infectología. Vigilancia virus respiratorios. Vigilancia virus respiratorios. 2015. Disponible en: http://www.sochinf.cl/portal/templates/ sochinf2008/documentos/2015/vigilancia jul_1_2015.pdf.

56.- Gilbert D N, Moellering R C, Chambers H F, Saag M S. La Guía Sanford para el tratamiento antimicrobiano 2016. 46th ed. México; 2016.

57.- Bal A M, Kumar A, Gould I M. Antibiotic heterogeneity: From concept to practice. Ann N Y Acad Sci 2010; 1213 (1): 81-91. DOI: 10.1111/j.1749-6632.2010.05867.x.

58.- Masterton R. Antibiotic heterogeneity. Int J Antimicrob Agents 2010; 36 (Suppl 3): S15-8. doi: 10.1016/S0924-8579(10)70005-4. 